\title{
Paraphrasing Strategy in EFL Ecuadorian B1 Students and Implications on Reading Comprehension
}

\author{
Isabel Escudero ${ }^{1}$, Narcisa Fuertes ${ }^{1} \&$ Ligia López ${ }^{1}$ \\ ${ }^{1}$ Universidad Nacional de Chimborazo, Riobamba, Ecuador \\ Correspondence: Isabel Escudero, Linguistic Competence Department, Universidad Nacional de Chimborazo, \\ Riobamba, Chimborazo, Av. Antonio José de Sucre Kl 1 1/2, Ecuador.
}

Received: October 28, 2018

Accepted: December 4, 2018 Online Published: December 7, 2018

doi: $10.5539 /$ elt.v12n1p56

URL: https://doi.org/10.5539/elt.v12n1p56

\begin{abstract}
Reading comprehension in Ecuadorian students has been mostly managed at a literal comprehension level, leaving out inferential and critical comprehension. This is because most of the articles students read require a high level of literacy and a good domain of comprehension strategies. One of these strategies is paraphrasing; therefore, the purpose of this research was to analyze the effects of paraphrasing and its implications on reading comprehension skills in English as a foreign language. This study was developed in B1 students enrolled at the 6th level of English at Linguistics Competence Department at Universidad Nacional de Chimborazo UNACH with a sample of 50 students. A base-line pre-test and a posttest to an experimental and control group were applied. The project implementation took ten sessions and students learned the techniques to effectively paraphrase and the pitfalls they should avoid when applying this strategy. The analysis of T-student test yielded that the experimental group outperformed the control group. The main results showed that once students learn the techniques and correctly apply them, it helped them out to go beyond the literacy level, applying an authentic reading comprehension of the text. Pedagogical implications about paraphrasing and reading comprehension are presented in the discussion.
\end{abstract}

Keywords: EFL students, paraphrasing, reading comprehension

\section{Introduction}

Reading is a receptive skill and it is one of the four linguistic skills taught and learned in English as a Foreign Language. It implies not only the capacity to understand the words but also the ability to understand the context of those words in the text, process them, relate them with what the student already knows and finally construct meaning. Once the student has constructed their own knowledge from what he/she has read, real comprehension can be shown, the output can be clear and meaningful and questions about the passage can be answered easily. On the other hand, paraphrasing is to be proven as a strategy that implies its basic elements such as lexis, semantics and syntax which work together to display real comprehension.

\subsection{The Current Situation of EFL Students in Regard to Reading Comprehension and Paraphrasing}

Hirano 2015 as cited in (Alghail \& Mahfoodh, 2016) determined that higher education nature of reading activities was one of the difficulties encountered by students in a Malaysian university. In addition, it is the fact that readings are much longer and more complex compared to the readings they were used to read in high school. Obviously, foreign language nature summed up, since it is more difficult to read texts in L2 due to the wide range of specialized and academic vocabulary (Clarke, 2018). Finally, students' poor level of literacy also contributed to the drawbacks of academic reading.

This study is not disconnected of the Ecuadorian reality. A student who starts college education may face many challenges related to reading due to the lack of reading culture which is evidenced in Ecuador since early childhood and throughout basic education and high school. For example, a study carried out by the University of Cuenca in 5th graders showed that multi-grade teaching practices in public schools, the few hours assigned to study L1 and the lack of interesting books caused poor reading skills development (Pedagogía, 2016). Additionally, findings related to high school students pointed out that adolescent girls showed a greater interest in reading over young boys, since the latter ones preferred to spend their free time in videogames and social networks (Education, 2017). It is obvious that this lack of scaffolding, has a negative impact on the good 
performance of undergraduate students in an academic setting (Anabelle, Cisneros, Shaw, \& Maloney, 2010).

As a result of poor reading skills, Ecuadorian college students have made palpable, on their papers, the inconsistency of what they read and what they want to communicate related to the text, noticing the lack of reading comprehension skills, measured in the capacity to understand main ideas and point out specific details, comprehend the lexicon and make inferences for meaningful contributions (Tierney \& Cunningham, 1980).

These relevant responses expected from students imply a whole process, which starts with reading, next paraphrasing and finally output. Nevertheless, most of students in Ecuadorian higher education settings admitted having developed a copy-page culture which has affected the quality of their papers and they have blamed this situation to academic grounds, firstly because of their poor reading skills and secondly because they have never been trained about how to use the paraphrasing strategy effectively. They have heard about paraphrasing and have thought it consisted basically on changing words, displaying, most of the time, a plagiarized version of the text. This background has affected negatively their reading comprehension skills since they show they are somehow good to answer questions related to specific details whereas they find it difficult to answer those which imply inferential and critical comprehension.

\subsection{Research Background and Gaps}

After some literature review regarding the effects of paraphrasing on reading comprehension, some aspects related to paraphrasing have been considered; for instance, RAP strategy (Read, Ask, Put), Neural Network Classification and other (Hagaman \& Casey, 2017) ("Improving the reading comprehension of primary-school students at frustration- level reading through the paraphrasing strategy training : A multiple-probe design study," 2017) (Rajkumar, 2010) These studies refer to have worked with paraphrasing but with other types of populations such as young learners and learners with reading difficulties. There are also studies which population's first language is English and the results are good since they do not have the difficulties presented by the population of this study due to the L2 (Khrismawan \& Widiati, 2013). The results of the mentioned studies, even though, are valid and can be generalized at any level of native English readers, still leave a gap to be researched. That is why this research pursues findings in students whose first language is not English and are learning it in a non-English speaking environment since just a limited number of studies have been found related to paraphrasing strategy with EFL students and its implications on reading comprehension.

\subsection{Reading Comprehension and Paraphrasing}

Reading comprehension is a metacognitive skill that has been studied for years and discussed for many authors. For a student to effectively comprehend a text many elements play a role, for example vocabulary, cognitive strategy instructions, metacognitive processes, motivation and self-regulation. Furthermore, it is necessary to realize that, most of the time, what is read is different of what is understood (Shi, 2012). For this reason, reading comprehension must take its first steps from early ages and it is the role of the class tutors to provide students with strategies that, with time and dedication, will become skills performed unconsciously by students when they become more experienced.

For a reader to be proficient, he/she should manage the three basic aspects of reading comprehension; literal, inferential and critical comprehension. Literal comprehension implies an understanding of what is exactly read on the text: main ideas, supporting details and lexis. Therefore, the reader can categorize, outline, and summarize. Similarly, inferential comprehension implies an understanding of what is meant or said between lines and again it may be present in main ideas, supporting details and lexis, so that the reader will be able to draw conclusions, predict, and determine the author's attitude and possible bias. Finally, critical comprehension involves a judgment of what the author says and an evaluation according to the reader's prior experience (Mistar, Zuhairi, \& Yanti, 2016). Silva and Cain (2015) mention that when the reader comprehends a text, it is easy for him/her to decode words and convey meaning which is expressed using semantics, syntax and background knowledge in order to construct a pattern of knowledge (Silva \& Cain, 2015).

Based on what has been mentioned and the experience of what is tested in the reading section of international tests such as TOELF, PTE academic and First certificate, the reader needs to understand the basic areas of the text; main ideas and details, lexical comprehension (literal comprehension) and inferential and critical comprehension. It is also based on the experience that students and teachers need to develop strategies that will allow them to increase their lexis, improve their use of grammar and activate their inferential and critical reading comprehension.

One of these strategies is paraphrasing, which is not only "put the text in your own words" as it was described by students under intervention, or at least, it is not as easy as it sounds. Two important contributions to this concept 
are added by Shi (2012); the reference of the source and the preservation of meaning. This last one was contributed by D'Angelo (1979) and cited by the same author (Shi, 2012). It is important to mention that paraphrasing intents to develop student's ability to process the given text and create an output that is more significant for them. In addition, the Latrobe University in the "Referencing and Paraphrasing Writing" states that "Poor paraphrasing is often the result of poor understanding of the text. Some students try to paraphrase at the sentence level rather than the ideas level". McNamara (2007) also finds that there is "a positive correlation between inaccurate paraphrases and poor comprehension of a text" (p. 477). This approach can be used to monitor their level of comprehension of the text they have (Kletzien, 2009) and according to it, go back to the original source, check and increase comprehension if necessary.

Some authors, as mentioned by Shi, 2012, describe the levels of paraphrasing which is closely related to the level of comprehension. For instance, if a student has not understood the text in a proper way, superficial paraphrasing will be carried out, thus it will consist only in a variation of words, re-order sentences, deletions or inclusions of too much of the original. In contrast, if the student level of comprehension increases, he/she will be able to provide substantial modifications, a reference of the author and include new characteristics by using inferential and critical thinking.

\subsection{The Meta-cognitive Process of Paraphrasing}

According to Kirkland \& Saunders cited by Lee, Yee et al. (2012) paraphrasing uses a step by step metacognitive structure. A similar concept is introduced by Choy and Cheah who mention that students are now changing their thinking paradigms based on Blooms' taxonomy, it est. analysis, synthesis, and evaluation which play a very important role in todays' learning processes (Chee et al., 2012). Paraphrasing implies a complete cognitive and metacognitive process in order to restate a sentence or paragraph in such a way that the new text changes the lexical and syntactic but keeps the semantic aspect (Khrismawan \& Widiati, 2013). In addition, paraphrasing includes key thinking skills such as comparing and contrasting, noticing similarities and differences, drawing conclusions and others Besides, a good level of vocabulary knowledge is a key component of comprehension and very important platform for paraphrasing and so is for reading comprehension (Faramarzi, Elekaei, \& Tabrizi, 2016).

The metacognitive objectives of this strategy are to produce a reflection about the thinking process when paraphrasing and provide an evaluation of how effective the strategy is. Some of the questions for this step may be; did my paraphrased version work? What things can I change/ improve/ or avoid next time? Does the new version of the text influences me in the same way the original text does? Am I using the paraphrasing strategy effectively? When students answer these questions, they explore a new way of comprehension.

\subsection{Techniques and Pitfalls of Paraphrasing}

Far from what it has been understood; paraphrasing is more than only changing words; therefore, the complete definition includes techniques that take the strategy one step forward. Some authors, for instance, include techniques such as changing the sentence structure (making sentences shorter or longer and changing the order of sentences and clauses), providing a reference, avoiding leaving out information, changing numbers by fractions, using synonyms and changing the word class (Karapetyan, 2005). In contrast, Kennedy and Smith cited by Hayuningrum, Herdiansari (2012), in the article Students' Problems in Writing Paraphrases in Research Paper Writing Class mentions eight pitfalls that have to be sidestepped: (1) misreading the original which leads to change the semantics of the text, (2) including too much of the original, (3) leaving out important information, (4) adding opinion, (5) summarizing rather than paraphrasing, (7) substituting inappropriate synonyms, (8) and forgetting to document (Hayuningrum, n.d.). This author also mentions that in order to avoid plagiarism, the so called word-for-word copying and the patchwork paraphrase which is the result of the cut-and-paste practice must be avoided.

\subsection{Hypotheses and Research Questions}

The hypotheses proposed for this study was if paraphrasing strategy affects the process of reading comprehension in EFL students.

The research questions were:

(1) What role does paraphrasing play in the EFL students' reading comprehension? Are there any changes in the reading skills after students learn to paraphrase?

(2) What are the students' common problems during the process of paraphrasing?

(3) What aspect of reading comprehension are mostly affected by paraphrasing? 


\section{Methodology}

The study was quasi-experimental as there was no randomization in subjects' selection. Groups were kept intact as students enrolled in the English course of the Linguistic Competence Department at UNACH. Due to the need of solving problems related to paraphrasing and reading comprehension; paraphrasing strategy was the independent variable and reading comprehension the dependent variable.

This study emerged from the research project "Paraphrasing: a methodology strategy and implications on reading comprehension" presented to the ICIT Institute of Sciences and Technology at Universidad Nacional de Chimborazo UNACH which took part of a rigorous evaluation process, achieving all the requirements, and scoring a mastery criterion 90/100 thus, it was approved for its implementation.

\subsection{Participant Characteristics}

The sample consisted of two groups selected from English regular courses at Linguistic Competence Department at Universidad Nacional de Chimborazo. Health science students were chosen as the experimental group and Engineering students were the control group. Even though students came from a wide variety of social, academic and demographic backgrounds; no exclusion criteria, or restriction was used, so that all students registered in every group were taken as research subjects it. est. intact samples. They first signed the informed consent agreeing to be considered subjects of study. The total population was 50 students, 25 in each group. They ranged between 20 and 23 years old. In the experimental group male accounted for $48 \%$ and female $52 \%$, whereas the control group females accounted for $35 \%$ and males $65 \%$. Although, they all were registered in the $6^{\text {th }}$ level (B1), their English language skills were heterogeneous and did not match their entry profile required for B1 which was determined by the diagnosis test taken at the beginning of the course.

In addition, the researchers were experimented English professors who developed a wide range of research to determine the paraphrasing techniques to be implemented in the study. Furthermore, they had a self-training process as well as planning and discussion sessions before and during the intervention application.

\subsection{The Instruments to Collect Data}

A pre-test was applied as a base-line and a post-test to probe the hypothesis. The base-line test consisted on the four skills of English language (reading, writing, listening and speaking) and the two subskills (grammar and vocabulary) as well as a sample of paraphrasing. This test determined the level of entrance of the two groups and the ability to paraphrase a text. It is necessary to mention that this test also exposed the need to deal with the three levels of reading comprehension (literal, inferential and critical comprehension). The post-test included a reading text and 20 reading comprehension items. The test was based on a reading text from Top Notch $3(\mathrm{~B} 1+)$ Pearson textbook, which is the base of the syllabus of the regular courses of English at UNACH. This test included the three basic sections tested on reading comprehension tests: main ideas, supporting details and lexis to test literal comprehension; in addition, it incorporated inferential and critical thinking questions. The test was validated by language and linguistics experts from other universities in the region using the technique of expert judgement in order to assess test difficulties, effectiveness of distracters, power to discriminate and time required, all according to the objectives set for the study. Also, to statistically support this validation, the instrument was evaluated using the Cronbach's Alpha test which determined a value of 0.85 probing that it is reliable for research purposes. Finally, during the intervention, samples of paraphrasing were taken to analyze the most common problems faced by students during paraphrasing and the researcher also recorded student's behaviors in observation cards.

\subsection{The Proposal Implementation Process}

On one hand, regarding the experimental group, a discussion of the reasons why paraphrasing is important in order to elude summarizing and avoid intellectual plagiarism was carried out as first step. They understood how important the strategy is concerning to their major and the application to their future reading and writing works.

Five readings texts from the same textbook Topnotch $3 \mathrm{~B} 1+$ Pearson $3^{\text {rd }}$ edition were used in order to progressively apply the different paraphrasing techniques. These 5 readings were related to general topics such as the five most effective work habits, holidays around the world, world problems, job qualifications, medical discoveries and global warming. Vocabulary and grammar structures found in each reading were previously learned during the unit development according to the syllabus for the $6^{\text {th }}$ level.

In the class sessions, the teacher used the Presentation, Practice and Production method to introduce topics related to paraphrasing. The presentation stage involved to model a memorized statement related to the reading text worked in the session. Later, teacher asked students to state what they understood in their own words. Teacher wrote both sentences on the board, guided students to analyze the key elements and highlight them in 
the original text. Then, compare with the students' statement and check accuracy and completeness. Finally, there was a time for questions to monitor understanding. Lastly, depending on the number of the specific session, the teacher would introduce/review/or recall the concept of paraphrasing and metacognition.

The practice stage used the clickable audio version of the reading from the textbook for students to review pronunciation, and the teacher provided them with some examples and exercises taken from the reading for students to identify and apply the specific strategy taught at that time. When applying the strategy, students were asked to write their version directly in the handout.

During the production stage, students again listened to and read the text, at the same time twice. Then, students scanned for specific information and subdivided the text in smaller sections. Next, students were asked to provide an oral paraphrased version of the main idea and details where teacher evaluated comprehension. Students recorded their versions on their mobile phones and then listened to and compared it with the text to see how accurate they were in keeping the main idea and details (semantics). After checking them, students were asked to provide a written paraphrased version of the subdivided sections aiming to test vocabulary usage (lexis) and grammar structures (syntax).

The class session topics were regarded to specific techniques used in paraphrasing strategy: use of synonyms, change word class, switch the order of phrases and clauses, make long sentences shorter, use concrete ideas instead of abstract ideas, change sentence structure like using passive voice instead of active voice, for numbers, use fractions in its place and finally provide a reference. Besides that, students were trained on how to dodge out pitfalls such as: forgetting to acknowledge source or author, misreading the original, including too much of the original, leaving out important information, adding their personal opinion, summarizing rather than paraphrasing, substituting inappropriate synonyms, expanding or narrowing the meaning. Students, worked on teacher-made exercises related to each topic. Each session lasted 2 hours and there were 10 regular sessions and 1 review session.

Before ending the implementation process, in the review session, a series of one hundred extra sentences with different grammar structures were developed by the teacher and paraphrased by students in class and at home to consolidate knowledge.

On the other hand, for the control group, a talk about why reading strategies are important and how fruitful to manage them effectively may be for their majors, was conducted before starting the experiment. Some of the results stated were that they would be able to understand texts in a better way and make use of the content as required. This group worked the same reading texts with the same length of time, but on different days and with a different method. The teacher conducted pre-reading and post reading strategies as proposed by the textbook. These strategies included: describing pictures or visual aids, vocabulary preview, brainstorming and group discussion to elicit prior knowledge of the topic. Graphic organizers, questioning, and exit slips as post-reading strategies. Teacher also included some Spanish translation and some explanations of the culture behind the context of the reading when necessary.

\section{Results}

In order to test the general hypothesis, the Statistic T-student was applied according to two factors; the normal behavior of the data which was established by the test Kolmogorov-Smirnov in SPSS and the number of data which is greater than 30 .

\subsection{Recruitment}

The research was carried out in a period of twelve months including four stages planning three months, researchers training two months, implementation 4 months and follow up three months. The implementation stage was applied in the same term for both experimental and control groups.

\subsection{Analysis of the First Research Question}

What role does paraphrasing play in the EFL students' reading comprehension? Are there any changes in the reading skills after students learn to paraphrase?

The analysis of the results of the posttest between the two groups was carried out and it is presented in table $\mathrm{N}^{\circ} 1$ 
Table 1. Posttest results - experimental and control group

\begin{tabular}{lllll}
\hline Group & Number of Students & Mean & Standard deviation & Standard error of the mean \\
\hline Experimental & 25 & 6.2278 & 1.25265 & 0.25053 \\
Control & 25 & 3.72 & 1.09075 & 0.21815 \\
\hline
\end{tabular}

This table shows the comparison of the means between the two groups after the intervention. The difference is statically significant between the two groups.

Table 2. T-test for independent samples

\begin{tabular}{|c|c|c|c|c|c|c|c|c|c|}
\hline \multicolumn{5}{|c|}{ Levene's test for equality of variances } & \multicolumn{5}{|c|}{ T-test for the equality of means } \\
\hline & \multirow[t]{2}{*}{$\mathrm{F}$} & \multirow[t]{2}{*}{ Sig. } & \multirow[t]{2}{*}{$\mathrm{t}$} & \multirow[t]{2}{*}{$\mathrm{gl}$} & \multirow{2}{*}{$\begin{array}{l}\text { Sig. } \\
\text { bilateral }\end{array}$} & \multirow[t]{2}{*}{ M.D } & \multirow[t]{2}{*}{$S_{D}$} & \multicolumn{2}{|c|}{ *Interval of difference } \\
\hline & & & & & & & & Inferior & Superior \\
\hline $\begin{array}{l}\text { Equal variance } \\
\text { assumed }\end{array}$ & 2.406 & .127 & 7.549 & 48 & .000 & 2.50778 & .33220 & 1.83985 & 3.17571 \\
\hline $\begin{array}{l}\text { Equal variances } \\
\text { not assumed }\end{array}$ & & & 7.549 & 47.109 & .000 & 2.50778 & .33220 & 1.83952 & 3.17603 \\
\hline
\end{tabular}

*95\% Confidence

The results show that the p-value is lower than the selected level of significance $(0.05)$ which leads to reject the null hypothesis since there is an improvement of the first variable for the experimental group according to the table number 1.

\subsection{Analysis of the Second Research Question}

What are the students' common problems during the process of paraphrasing?

Data regarding this research question was collected only from the experimental group who were under intervention. Three samples of the same paraphrasing practice were gathered; number of errors in each technique were tabulated and shown in figure $\mathrm{N}^{\circ} 1$. The order of the techniques are presented.

Technique 1 Expanding or narrowing the meaning

Technique 2 Substituting inappropriate synonyms

Technique 3 Adding opinion

Technique 4 Changing the order of phrases and clauses

Technique 5 Changing sentence structure

Technique 6 Leaving out important information

Technique 7 Using concrete ideas instead of abstract ideas.

Technique 8 Making long sentences shorter

Technique 9 Providing a reference

Technique 10 Changing word class

Technique 11 Using fractions instead of numbers 


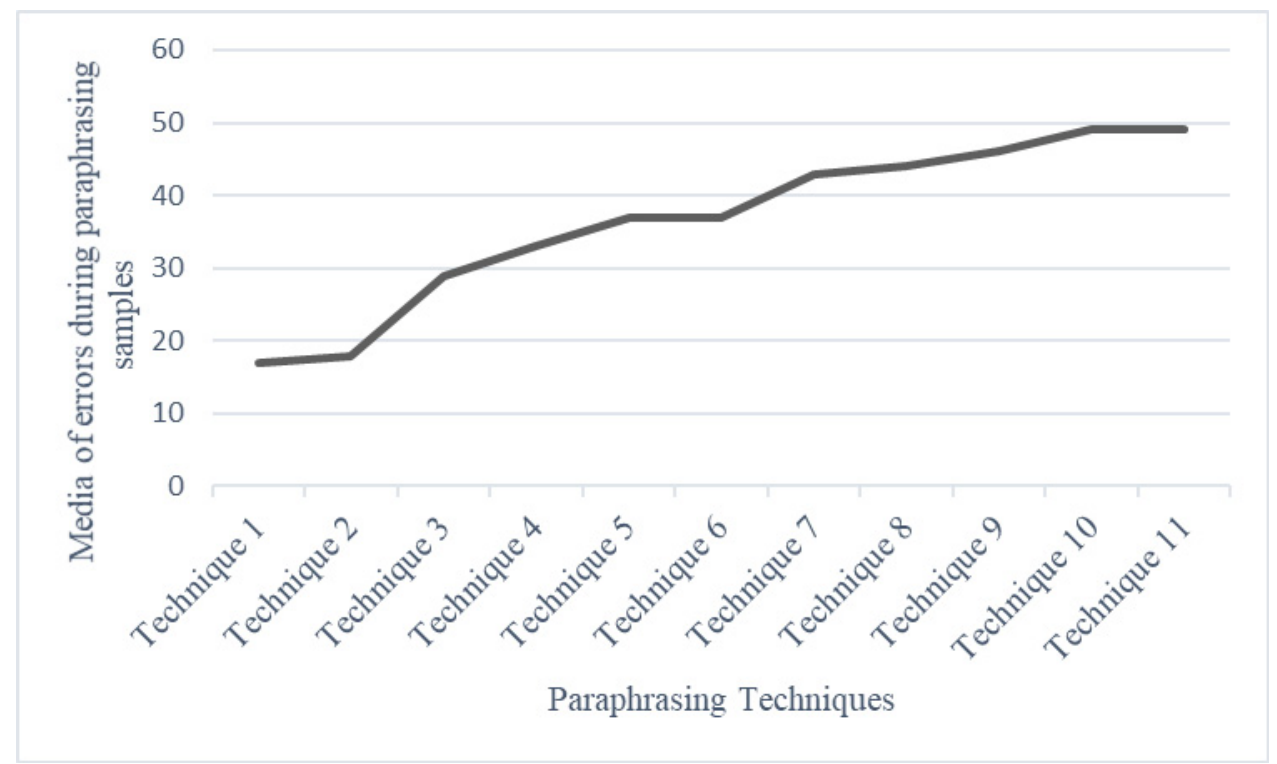

Figure 1. Students' most common errors on paraphrasing

Regarding the second research question, the paraphrasing samples showed that the 5 most common errors were made in the following techniques, from the highest to the lowest media of errors:

First difficulty: (Technique 11) Using fractions instead of numbers,

Second difficulty: (Technique 10) Changing word class,

Third difficulty: (Technique 9) Providing a reference,

Fourth difficulty: (Technique 8) Making long sentences information,

Firth difficulty: (Technique 7) Using concrete ideas instead of abstract ideas shorter,

Sixth difficulty: (Technique 6) Leaving out important information.

\subsection{Analysis of the Third Research Question}

(3) What aspects of reading comprehension are most affected by paraphrasing?

Table 3. Group statistics

\begin{tabular}{llllll}
\hline & Group & Number & Mean & Standard deviation & Standard error of the mean \\
\hline Main Ideas & Experimental & 25 & 7.0000 & 1.70783 & 0.34157 \\
& Control & 25 & 3.7600 & 1.39284 & 0.27857 \\
Lexical & Experimental & 25 & 4.0833 & 0.69358 & 0.13872 \\
\multirow{4}{*}{ Critical and } & Control & 25 & 1.9333 & 1.24931 & 0.24986 \\
Inferential thinking & Experimental & 25 & 7.6000 & 2.26078 & 0.45216 \\
& Control & 25 & 5.4667 & 2.23192 & 0.44638 \\
\hline
\end{tabular}


Table 4. Independent sample test Comparison between the experimental and control group posttest

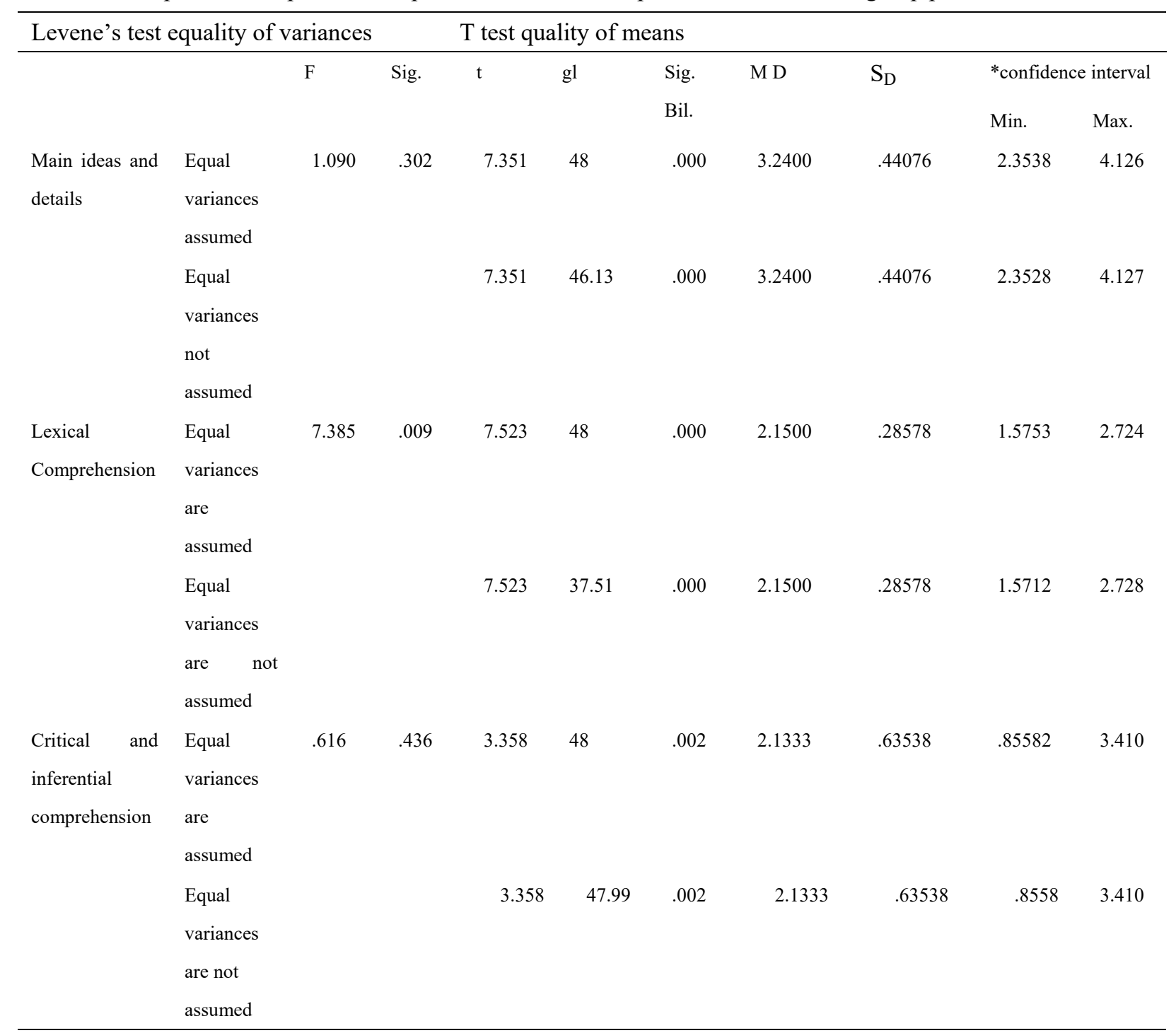

$*$ T for a $95 \%$.

This table shows that the three aspects tested in reading comprehension were outperformed by experimental group in the posttest which $P$ value is statistically significant.

\subsection{Drawbacks of the Experiment}

Even though the results were positive and the hypothesis was proven, it is necessary to identify some the downsides detected during the study and recorded in the teacher's observation cards:

First, participants dedicated limited time for reading as it was mentioned in the statement of the current situation of Ecuadorian students. During informal conversations recorded in observation cards, they admitted not to read more than an hour every day and they do it only because they are required to. Moreover, they noted a restricted self-motivation for reading for pleasure in Language 2. They basically read only their notes or books for tests, lessons or because they must memorize some processes or procedures, therefore the group presented low ability to inferentially or critically comprehend.

Secondly, other problem that affected the study was the lack of commitment with self-improvement regarding the use of paraphrasing strategy. Students felt that paraphrasing in English was difficult and rejected to do practice by themselves, they wanted to count on the teacher's support and guide in every lesson. Only a half of students did assigned homework and the rest copied. This was notorious because they could not apply the 
studied techniques efficiently and needed more control and feedback. As a result, this fact affected negatively to the study. Furthermore, students' perceptions on paraphrasing summed up, since they though it consisted only on changing words by using synonyms, and sometimes, they were unwilling to take one step forward. In fact, the teacher had to push them by assigning grades to every practice they did in class and had to ask them to come to extra hours of practice to carry our intervention as planned.

Thirdly, their level of English worked against those whose level of entrance was lower than expected. They showed they struggled even with changing synonyms and depended on their mobile devices to carry out activities. They found it really difficult to apply techniques such as using a variation of words verb to noun.

Finally, as stated before, paraphrasing strategy seemed to be very difficult to apply for poor readers, so that the time of intervention was short compared to the high academic level required for developing paraphrasing strategy. Besides the work academic load demanded by the major preventing them from promoting other skills including the ability to read in English.

\section{Discussion}

Results of the base-line pretest showed that students in both experimental and control group performed similarly regarding the application of paraphrasing strategies; this finding is alike to the results of the study at the University of Iowa regarding the Effects of the Paraphrasing Strategy on Expository Reading Comprehension. In addition, these findings showed that learners take advantage from a paraphrasing strategy as an explicit instructions model (Hua, Woods-groves, Ford, \& Nobles, 2014). These findings, suggest a coincidence with the results of the study conducted with university students at UNACH since the experimental group outperformed the media results in 2.5 of the control group in the post test after the intervention. Therefore, the findings of the study suggest that providing paraphrasing instruction in an explicit basis can improve reading comprehension of university students.

In the study: "Paraphrasing in English Academic Writing by Thai Graduate Students" findings revealed that, one of the most common errors in students paraphrasing practices is plagiarism because they do not cite properly, (Ideas, Paper, \& Louis, 2017). This finding is also largely consistent with the study at the National Kaohsiung Normal University conducted in an EFL academic setting, which found that the most common error was inappropriately reference of source texts, both studies are consistent with the difficulty found on this research that is not providing a reference, assigned as the third most common paraphrasing difficulty. Even though it was the first one on the first sample taken.

Another study concerning Students' Behaviors and Views of Paraphrasing and Inappropriate Textual Borrowing in an EFL suggested that the most common errors was the patch-writing, i.e. students misused synonyms and syntactic adjustments, coming up with distortion of the semantics of the original text; (Liao \& Tseng, 2010); this finding is entailing the results of this study concerning the most common difficulties related to substituting inappropriate synonyms and changing sentence structure both of them affecting the semantic completeness of the text.

Durkin and et al. (1995) state that effective reading involves a purposeful process aimed to activate cognitive and metacognitive procedures, that is critical thinking and that comprises understanding meaning of text, organizing information in a logical mode, and restructuring what is cited by (Hua et al., 2014). In the study regarding the components of paraphrase evaluations conducted at McnaMara University of Memphis, Tennessee, results indicated that semantic completeness and syntactic similarities showed higher relationship to paraphrase quality than lexical similarity (Systems, 2009). These findings showed consistency with this study in the way that main ideas, critical inferential thinking included in semantics revealed the highest mean in relation to lexical comprehension.

The implication of the results of this research toward the teaching of paraphrasing is that the techniques that the strategy implies are very valid to be taught at higher education level for EFL students as well as first language students because paraphrasing fosters reading at all its comprehension levels. Teachers are encouraged to implement this technique in their syllabus as part of developing reading and writing skills. Furthermore, paraphrasing could be applied at every level of education as it is reading, for example paraphrasing can start at the first levels during elementary instruction by using sentences or short quotes. As stated by Rachel Lynette (2014) in her teachers' blog there are some approaches that can be used to progressively enable students to paraphrase. However, instruction does not have to stop, but it has to continue until students 'comprehension meets the acceptable or desired level (Hagaman, Casey, \& Reid, 2016). Therefore, this strategy does not have to be diminished or forgotten during college training since they are the most likely to commit plagiarism due to the nature of their assignments. 
Regarding reading comprehension, this study suggests that teachers should pay especial attention to this skill of language, particularly in Ecuadorian context where it has been demonstrated that literal comprehension is mostly developed. Every teacher at every level is required to look for strategies that stimulate learners to activate the three levels of reading comprehension (literal, inferential and critical). Paraphrasing can be one of them as it has been proved in this study that it develops reading comprehension.

\subsection{Conclusions}

Explicit instruction on paraphrasing techniques and awareness of common errors conduct to effective reading comprehension. Future researchers should develop this line of research with a focus on simplification of strategies and determine criteria to achieve the paraphrasing quality of source texts.

The most common errors during the process of paraphrasing consist of syntactic similarities, plagiarism, and semantic completeness. The implementation of effective paraphrasing strategies might contribute to decrease plagiarism matters and increase academic upright standards. In addition, it is important to establish a simple and accurate assessment process on paraphrasing usage in order to facilitate appropriate feedback.

The aspects of reading comprehension mostly affected by paraphrasing are semantic completeness and syntactic similarities; that is learners are able to step into inferential and critical comprehension.

\section{Acknowledgments}

Recognition is given to Universidad Nacional de Chimborazo and its Research Institute ICITS for the support and advice in the project preparation and for assigning time in the researcher's work hours to implement the proposal. Researchers also thank the expert professors for reviewing the test and doing the prof-reading of this manuscript, and the statistic professionals to validate the data collected and results.

\section{References}

Alghail, A. A. A., \& Mahfoodh, O. H. A. (2016). Academic reading difficulties encountered by international graduate students in a Malaysian university. Issues in Educational Research, 26(3), 369-386.

Anabelle, K., Cisneros, S., Shaw, D. G., \& Maloney, D. P. (2010). Impact Of Extensive Reading On Ecuadorian Learners 'Attitudes Toward L2 Reading : A Qualitative Research Study.

Chee, S., Perak, C., Campus, B., Tunku, K., Rahman College, A., Mun, M., \& Lee, Y. (2012). Effects of Teaching Paraphrasing Skills to Students Learning Summary Writing in ESL. Journal of Teaching and Learning, 8(2). https://doi.org/10.22329/jtl.v8i2.3145

Clarke, D. C. (2018). Student responses to vocabulary learning strategies on an ESAP course. ELT Journal, (March), 1-10. https://doi.org/10.1093/elt/ccy001

Education, E. (2017). Improving the reading comprehension of primary-school students at frustration-level reading through the paraphrasing strategy training: A multiple-probe design study, 1-19.

Faramarzi, S., Elekaei, A., \& Tabrizi, H. H. (2016). Critical Thinking, Autonomy, and Lexical Knowledge of Iranian EFL Learners. Theory and Practice in Language Studies, 6(4), 878-885. https://doi.org/http://dx.doi.org/10.17507/tpls.0604.28

Hagaman, J. L., \& Casey, K. J. (2017). Paraphrasing Strategy Instruction in Content Area Text. Intervention in School and Clinic, 52(4), 210-217. https://doi.org/10.1177/1053451216659468

Hagaman, J. L., Casey, K. J., \& Reid, R. (2016). Paraphrasing strategy instruction for struggling readers. Preventing School Failure, 60(1), 43-52. https://doi.org/10.1111/bdi.12538

Hayuningrum, H. (n.d.). S tudents ' Problems in Writing Paraphrases in Research Paper Writing Class, 15(1), 133-147.

Hua, Y., Woods-groves, S., Ford, J. W., \& Nobles, K. A. (2014). Effects of the Paraphrasing Strategy on Expository Reading Comprehension of Young Adults with Intellectual Disability, 49(3), 429-439.

İlhan, İ. (2017). Improving the reading comprehension of primary-school students at frustration- level reading through the paraphrasing strategy training: A multiple-probe design study. International Elecronic Journal of Elementary Education, 10(1). https://doi.org/10.26822/iejee.2017131894

Karapetyan, M. (2005). PARAPHRASING DOs AND DON ‘ T s, 32-40.

Khrismawan, B., \& Widiati, U. (2013). Students' Perceptions About Paraphrasing and Their Cognitive Processes in Paraphrasing. TEFLIN Journal, 24(2), 135-157. https://doi.org/10.15639/TEFLINJOURNAL.V24I2/135 $-157$ 
Kletzien, S. B. (2009). Paraphrasing: An Effective Comprehension Strategy. The Reading Teacher, 63(1), 73-77. https://doi.org/10.1598/RT.63.1.7

Mistar, J., Zuhairi, A., \& Yanti, N. (2016). Strategies Training in the Teaching of Reading Comprehension for EFL Learners in Indonesia. English Language Teaching, 9(2), 49. https://doi.org/10.5539/elt.v9n2p49

Pedagogía, C. D. E. (2016). Universidad Politécnica Salesiana Juan Carlos Tenesaca Campoverde Tutor.

Rajkumar, A. (2010). Paraphrase Recognition using Neural Network Classification, 1(29), 42-47.

Shi, L. (2012). Rewriting and paraphrasing source texts in second language writing. Journal of Second Language Writing, 21(2), 134-148. https://doi.org/10.1016/j.jslw.2012.03.003

Silva, M., \& Cain, K. (2015). The relations between lower and higher level comprehension skills and their role in prediction of early reading comprehension. Journal of Educational Psychology, 107(2), 321-331. https://doi.org/10.1037/a0037769

Tierney, R. J., \& Cunningham, J. W. (1980). Research on teaching reading comprehension. Handbook of Research on Reading.

\section{Copyrights}

Copyright for this article is retained by the author(s), with first publication rights granted to the journal.

This is an open-access article distributed under the terms and conditions of the Creative Commons Attribution license (http://creativecommons.org/licenses/by/4.0/). 